\title{
Worldwide trends in quantity and quality of published articles in the field of infectious diseases
}

\author{
Ioannis A Bliziotis ${ }^{1,2}$, Konstantinos Paraschakis ${ }^{2}$, Paschalis I Vergidis ${ }^{2}$, \\ Antonia I Karavasiou ${ }^{2}$ and Matthew E Falagas*1,2,3
}

\author{
Address: ${ }^{1}$ Alfa Institute of Biomedical Sciences(AIBS), Athens, Greece, ${ }^{2}$ Alfa HealthCare, Athens, Greece and ${ }^{3}$ Department of Medicine, Tufts \\ University School of Medicine, Boston, Massachusetts, USA \\ Email: Ioannis A Bliziotis - j.bliziotis@alfahc.gr; Konstantinos Paraschakis - s6990054@yahoo.com; \\ Paschalis I Vergidis - pvergidis@hotmail.com; Antonia I Karavasiou - a.karavasiou@alfahc.gr; Matthew E Falagas* - matthew.falagas@tufts.edu \\ * Corresponding author
}

Published: 21 March 2005

BMC Infectious Diseases 2005, 5:16 doi:10.1186/1471-2334-5-16

This article is available from: http://www.biomedcentral.com/I47I-2334/5//6

(c) 2005 Bliziotis et al; licensee BioMed Central Ltd.

This is an Open Access article distributed under the terms of the Creative Commons Attribution License (http://creativecommons.org/licenses/by/2.0), which permits unrestricted use, distribution, and reproduction in any medium, provided the original work is properly cited.
Received: 26 November 2004

Accepted: 21 March 2005

\begin{abstract}
Background: Trying to confront with the widespread burden of infectious diseases, the society worldwide invests considerably on research. We evaluated the contribution of different world regions in research production in Infectious Diseases.

Methods: Using the online Pubmed database we retrieved articles from 38 journals included in the "Infectious Diseases" category of the "Journal Citation Reports" database of the Institute for Scientific Information for the period 1995-2002. The world was divided into 9 regions based on geographic, economic and scientific criteria. Using an elaborate retrieval system we obtained data on published articles from different world regions. In our evaluation we introduced an estimate of both quantity and quality of research produced from each world region per year using: (I) the total number of publications, (2) the mean impact factor of publications, and (3) the product of the above two parameters.
\end{abstract}

Results: Data on the country of origin of the research was available for 45,232 out of 45,922 retrieved articles $(98.5 \%)$. USA and Western Europe are by far the most productive regions concerning publications of research articles. However, the rate of increase in the production of articles was higher in Eastern Europe, Africa, Latin America and the Caribbean, and Asia during the study period. The mean impact factor is highest for articles originating in the USA (3.42), while it was 2.82 for Western Europe and 2.73 for the rest of the world ( 7 regions combined).

Conclusion: USA and Western Europe make up a striking $80 \%$ of the world's research production in Infectious Diseases in terms of both quantity and quality. However, all world regions achieved a gradual increase in the production of Infectious Diseases articles, with the regions ranking lower at present displaying the highest rate of increase.

\section{Background}

Infectious diseases constitute a major health problem both in developed and developing countries. Old and emerging infectious diseases contribute substantially to morbidity and mortality worldwide. For this reason, the society invests considerably on infectious diseases 
research, in order to achieve scientific progress and develop new therapeutic interventions.

The research productivity by various world regions has been studied for several biomedical fields. In general, the USA and Western Europe are the leaders of global biomedical research, although their relative contribution varies for different fields of research [1-4]. Several studies have focused on the scientific production of European Union's countries, in various biomedical fields, including Infectious Diseases [5-7]. However, the literature lacks studies estimating the quantity and quality of worldwide research production in Infectious Diseases. The purpose of our study was to evaluate the contribution of different world regions in scientific research in the field of Infectious Diseases. We also evaluated the trends in quality and quantity of published articles from different world regions.

\section{Methods}

We used the electronic PubMed database [8] and data from the Journal Citation Reports (JCR) database of the Institute for Scientific Information (ISI) [9]. We searched for articles included both in the "Infectious Diseases" category of the JCR and in PubMed database. Articles published prior to 1995 were not included in the analysis, because the full address of the authors of the papers was frequently not registered in PubMed prior to this year. Because JCR had available data up to the year 2002 at the time of our analysis, our data collection and evaluation refers to the period 1995-2002. A total of 38 journals were included. Two independent investigators conducted the data collection (IAB, PIV).

For the purpose of this study, the world was divided into 9 regions based on a combination of geographic, economic and scientific criteria [10]. The 9 regions are Western Europe, Eastern Europe, United States of America (USA), Canada, Latin America and the Caribbean, Africa, Japan, Asia (excluding Japan), and Oceania.

In our search of different fields in the Pubmed database we used a phrase consisting of four parts joined together by the so-called Boolean operators, i.e. AND, OR, and NOT. Each search was limited to a specific year using the "Limits" function, which is incorporated in the search engine. We only analyzed data on original articles and reviews, excluding publication types, such as letters, editorials, and news reports. For example in order to search for articles published in the "Journal of Infectious Diseases" and whose first author's address was in Europe, we used the following text: Journal of Infectious Diseases [journal] AND journal article [pt] AND (Andorra [AD] OR Austria $[A D]$ OR... Wales $[A D]$ ) NOT (Australia [AD] OR Canada $[A D] O R \ldots .$.$) . In the first parenthesis of the search phrase,$ the countries of the implicated region are included. In the second parenthesis, after the word NOT, certain addresses are excluded in order to avoid double counting.

Subsequently, the results of these searches (the number of articles produced by each world region in a specific journal within a year) were summed up. For confirmation, the sum of articles produced by all different world regions in a journal, was compared to the actual total number of articles published in that journal for a specific year. This number was obtained from PubMed without using any address limits. Using this methodology we were able to cross-examine missed or unretrieved addresses. This occurred occasionally, in cases of articles with no address registered, and in cases of articles where only the affiliated institution or the city (not the country) was recorded. If less than $5 \%$ of the total articles of a specific journal during a year had missing addresses, we did not include these articles in our calculations, assuming that the numerical error was not significant. On the other hand, if more than $5 \%$ of the total articles of a specific journal during a year, had missing addresses, we performed searches for the author's address by checking other articles of the same author within the same year.

The number of published articles was considered as an index of quantity of research productivity. The mean impact factor of the published articles was considered as an index of quality of research productivity. Finally, the product of the number of articles published in a journal multiplied by the impact factor of the journal, for the year studied, was considered as an index evaluating combined the quantity and quality of research productivity. The sum of these products from all journals, for each world region within a year, was named "total product" for each region within the studied year. The impact factor for each journal was obtained from the JCR database of the ISI.

To further evaluate factors associated with the research published in Infectious Diseases journals we used relevant "World Development Indicators" [11] from the online databases of the World Bank. The research productivity of different world regions (estimated by the "total product") was evaluated in relation to total population, gross domestic product (GDP) in standard 1995 US dollars, and gross national income (GNI) per capita (Atlas method).

We used the absolute figures and the average annual rates of increase of scientific output (research productivity) of different world regions to calculate future performance using a projection model. Also, we performed correlation statistical analysis of the absolute numbers of published articles between the different world regions during the years of the study period (1995-2002) using Pearson 
Table I: Title of journals included in the field of Infectious Diseases of the Institute for Scientific Information (ISI) indexed both by ISI and PubMed.

\begin{tabular}{|c|c|}
\hline Title of journal & Study period \\
\hline AIDS & $1995-2002$ \\
\hline AIDS Patient Care STDS & 2002 \\
\hline AIDS Research and Human Retroviruses & $1995-2002$ \\
\hline American Journal of Infection Control & $1995-2002$ \\
\hline Antiviral Therapy & $2000-2002$ \\
\hline BMC Infectious Diseases & 2002 \\
\hline Clinical and Diagnostic Laboratory Immunology & $1995-2002$ \\
\hline Clinical Infectious Diseases & $1995-2002$ \\
\hline Clinical Microbiology and Infection & 2002 \\
\hline Current Opinion in Infectious Diseases & $2000-2002$ \\
\hline Diagnostic Microbiology and Infectious Disease & $1995-2002$ \\
\hline Emerging Infectious Diseases & $1995-2002$ \\
\hline Epidemiology and Infection & $1995-2002$ \\
\hline European Journal of Clinical Microbiology and Infectious Diseases & $1995-2002$ \\
\hline Infection & $1995-2002$ \\
\hline Infection and Immunity & $1995-2002$ \\
\hline Infection Control and Hospital Epidemiology & $1995-2002$ \\
\hline Infectious Agents and Disease & $1995-1996$ \\
\hline Infectious Disease Clinics of North America & $1995-2002$ \\
\hline International Journal of Antimicrobial Agents & $2000-2002$ \\
\hline International Journal of Hygiene and Environmental Health (prior to 1999: Zentralblatt fur hygiene und umweltmedizin) & $1997-2002$ \\
\hline International Journal of STD \& AIDS & $1995-2002$ \\
\hline International Journal of Tuberculosis and Lung Disease & $1998-2002$ \\
\hline $\begin{array}{l}\text { JAIDS-Journal of Acquired Immune Deficiency Syndromes (prior to 1998: Journal of Acquired Immune Deficiency Syndromes and } \\
\text { Human Retrovirology) }\end{array}$ & $1995-2002$ \\
\hline Japanese Journal of Infectious Diseases & $2000-2002$ \\
\hline Journal of Antimicrobial Chemotherapy & $1995-2002$ \\
\hline Journal of Hospital Infection & $1995-2002$ \\
\hline Journal of Human Virology & $2001-2002$ \\
\hline Journal of Infection & $1995-2002$ \\
\hline Journal of Viral Hepatitis & $1997-2002$ \\
\hline Leprosy Review & $1997-2002$ \\
\hline Microbial Drug Resistance & $1997-2002$ \\
\hline Pediatric AIDS and HIV Infection & 1997 \\
\hline Pediatric Infectious Disease Journal & $1995-2002$ \\
\hline Scandinavian Journal of Infectious Diseases & $1995-2002$ \\
\hline Sexually Transmitted Diseases & $1995-2002$ \\
\hline Sexually Transmitted Infections (prior to 1997: Genitourinary Medicine) & $1999-2002$ \\
\hline The Journal of Infectious Diseases & $1995-2002$ \\
\hline
\end{tabular}

correlation testing. In addition, we performed correlation statistical analysis to examine the research productivity of the specified world regions compared with the total world production.

\section{Results}

The journals that were included in our analysis are shown in Table 1. Using the methodology described above, we managed to retrieve and categorize 45,232 out of 45,922 articles, (98.5\%) from the implicated journals indexed in Pubmed during the study period. The total production of articles in each defined world region, as well as the relative contribution of each region to the total production in the field of Infectious Diseases, is displayed in Table 2. As shown in this table, USA and Western Europe are by far the most productive regions $(79.8 \%$ of the articles published worldwide, throughout the whole period studied, came from these two regions). As expected, the difference between the USA and Western Europe increases when both the number of articles and impact factor are taken into account, due to the higher impact factor that USA had throughout the study period. In the years 2000-2002 Western Europe's production exceeded that of the USA, although USA researchers produced more articles in all previous years. The last column shows the "total product" 
Table 2: Number of articles published in journals included in the "Infectious Diseases" category of "Journal Citation Report" database and indexed by PubMed, from different world regions, for the period 1995-2002.

\begin{tabular}{|c|c|c|c|c|c|c|c|c|c|c|}
\hline \multirow[b]{2}{*}{$\begin{array}{l}\text { WORLD } \\
\text { AREAS }\end{array}$} & \multicolumn{10}{|c|}{ Number of articles (\% percentage within a calendar year) } \\
\hline & 1995 & 1996 & 1997 & 1998 & 1999 & 2000 & 2001 & 2002 & $1995-2002$ & 1995-2002* \\
\hline USA & $\begin{array}{r}2118 \\
(\mathbf{4 6 . 9 8 )}\end{array}$ & $\begin{array}{r}2078 \\
(45.09)\end{array}$ & $\begin{array}{r}2162 \\
(43.66)\end{array}$ & $\begin{array}{r}2425 \\
(\mathbf{4 2 . 8 6})\end{array}$ & $\begin{array}{r}2346 \\
(40.27)\end{array}$ & $\begin{array}{r}2530 \\
(\mathbf{3 8 . 9 2})\end{array}$ & $\begin{array}{r}2543 \\
(\mathbf{3 8 . 4 8 )}\end{array}$ & $\begin{array}{r}2481 \\
(37.76)\end{array}$ & $\begin{array}{r}18683 \\
(41.30)\end{array}$ & 63804 \\
\hline $\begin{array}{l}\text { Western } \\
\text { Europe }\end{array}$ & $\begin{array}{r}1673 \\
(37.1 I)\end{array}$ & $\begin{array}{r}1804 \\
(39.14)\end{array}$ & $\begin{array}{r}1863 \\
(\mathbf{3 7 . 6 2})\end{array}$ & $\begin{array}{r}2136 \\
(\mathbf{3 7 . 7 5})\end{array}$ & $\begin{array}{r}2248 \\
(38.59)\end{array}$ & $\begin{array}{r}2577 \\
(\mathbf{3 9 . 6 5 )}\end{array}$ & $\begin{array}{r}2579 \\
(39.03)\end{array}$ & $\begin{array}{r}2539 \\
(\mathbf{3 8 . 6 4})\end{array}$ & $\begin{array}{r}17419 \\
(38.51)\end{array}$ & 49033 \\
\hline $\begin{array}{l}\text { Asia } \\
\text { (excluding } \\
\text { Japan) }\end{array}$ & $175(3.88)$ & $160(3.47)$ & $235(4.75)$ & $317(5.60)$ & $316(5.42)$ & $376(5.78)$ & $413(6.25)$ & $437(6.65)$ & $2429(5.37)$ & 5927 \\
\hline Japan & $106(2.35)$ & $|4|(3.06)$ & 177 (3.57) & 135 (2.39) & $226(3.88)$ & $258(3.97)$ & $273(4.13)$ & $260(3.96)$ & $1576(3.48)$ & 4113 \\
\hline Canada & 155 (3.44) & $126(2.73)$ & $|5|$ (3.05) & $179(3.16)$ & $181(3.11)$ & 194 (2.98) & $183(2.77)$ & 207 (3.15) & 1376 (3.04) & 4510 \\
\hline $\begin{array}{l}\text { Latin } \\
\text { America } \\
\text { and } \\
\text { Caribbean }\end{array}$ & 76 (1.69) & $82(1.78)$ & $101(2.04)$ & $127(2.24)$ & $130(2.23)$ & 154 (2.37) & $173(2.62)$ & $189(2.88)$ & $1032(\mathbf{2 . 2 8})$ & 2978 \\
\hline Oceania & 89 (1.97) & $108(2.34)$ & II I (2.24) & I $38(2.44)$ & $142(2.44)$ & 155 (3.97) & $144(2.18)$ & I 45 (2.2I) & $1032(\mathbf{2 . 2 8})$ & 3153 \\
\hline Africa & 70 (I.55) & $66(1.43)$ & 97 (1.96) & $137(2.42)$ & $159(2.73)$ & $|5|(2.32)$ & $177(2.68)$ & $153(2.33)$ & $1010(2.23)$ & 2913 \\
\hline $\begin{array}{l}\text { Eastern } \\
\text { Europe }\end{array}$ & 46 (1.02) & $44(0.95)$ & $55(1.11)$ & $64(1.13)$ & 78 (1.34) & $105(1.62)$ & $123(1.86)$ & $160(2.43)$ & 675 (I.49) & 1325 \\
\hline Total & $4508(100)$ & $4609(100)$ & $4952(100)$ & $5658(100)$ & $5826(100)$ & $6500(100)$ & $6608(100)$ & $657 I(100)$ & $\begin{array}{r}45232 \\
(100)\end{array}$ & 137756 \\
\hline
\end{tabular}

*Number of articles published multiplied by their impact factor

of research published in the field of Infectious Diseases for each region for the whole study period.

We observed a continuous increase in the production of research articles from all world regions during the period 1995-2002 (Table 2). There was a strong and statistically significant correlation between the absolute numbers of published articles between the different world regions during the years of the study period (1995-2002). The median (range) of the Pearson correlation test values between comparisons of 36 possible couples of the specified 9 world regions was $0.88(0.48-0.99)$. Thirty of 36 comparisons had statistical significance at levels $<0.05$ (24 of them had statistical significance at levels $<0.01$ ). The comparisons that did not have statistical significance ( $p>0.05$ ) were between world regions with relative small numbers of published articles in the field of Infectious Diseases.

In addition, a strong and statistically significant correlation was noted between the annual research production of the specified world regions with that of the total world production; specifically the median (range) of Pearson correlation test results of these analyses were 0.94 (0.70$0.99)$. However, the rate of increase of research productivity in the field of Infectious Diseases was higher in Eastern Europe, Africa, Latin America and the Caribbean, and Asia. Using a projection model we estimated that these regions would reach USA's production level in 23 years and Western Europe's production level in 29 years, provided that each region maintains the average rate of increase of research production achieved in the 8-yearperiod studied.

Table 3 presents the mean impact factor of published articles in the field of Infectious Diseases for each region in the studied years. A mean value of the impact factor is also presented for the whole 8-year-period. The mean impact factor, for the whole period, is highest for articles originating in the USA. Interestingly, Canada ranks second and Western Europe ranks sixth regarding the mean impact factor of published articles. Eastern Europe has the lowest mean impact factor among all world regions.

Figure 1 depicts the worldwide trends of research productivity in the period 1995-2002. USA ranks first among all studied world regions, even during the period 2000-2002 in which investigators from Western Europe published a greater number of articles than investigators from USA. Eastern Europe had the most significant relative growth in the "total product" of research between 1995 and 2002.

Table 4 presents the quality and quantity of published research adjusted for the regional population and to the gross national income per capita (GNIPC). Specifically, it presents the ratio of scientific "total product" per population divided by the gross national income per capita for each region annually and the respective mean ratio for the 
Table 3: Mean impact factor of articles published in journals included in the "Infectious Diseases" category of "Journal Citation Report" database and indexed by Pubmed, from different world regions, for the period 1995-2002.

\begin{tabular}{|c|c|c|c|c|c|c|c|c|c|}
\hline \multirow[b]{2}{*}{ WORLD AREAS } & \multicolumn{9}{|c|}{ Mean impact factor } \\
\hline & 1995 & 1996 & 1997 & 1998 & 1999 & 2000 & 2001 & 2002 & $\begin{array}{l}1995-2002\left(25^{\text {th }} \text { percentile, }\right. \\
\left.\text { median, } 75^{\text {th }} \text { percentile }\right)\end{array}$ \\
\hline USA & 3.08 & 3.44 & 3.12 & 3.26 & 3.47 & 3.60 & 3.71 & 3.54 & $3.42(2.293 .5 I 4.2 I)$ \\
\hline Canada & 2.88 & 3.71 & 2.91 & 3.00 & 3.29 & 3.48 & 3.49 & 3.43 & $3.28(2.083 .204 .18)$ \\
\hline Oceania & 2.69 & 3.17 & 3.01 & 2.84 & 2.75 & 3.53 & 3.28 & 2.99 & 3.05 (1.79 2.80 4.18) \\
\hline Africa & 2.83 & 2.87 & 3.12 & 2.46 & 3.00 & 2.87 & 3.01 & 2.90 & 2.89 (1.63 2.20 4.18) \\
\hline Latin America and Caribbean & 2.62 & 3.13 & 2.69 & 2.84 & 2.87 & 2.97 & 2.70 & 3.14 & 2.89 (1.77 2.634 .04$)$ \\
\hline Western Europe & 2.46 & 2.91 & 2.56 & 2.68 & 2.85 & 2.97 & 3.02 & 2.89 & 2.82 (I.4I 2.363 .93$)$ \\
\hline Japan & 2.77 & 3.23 & 2.80 & 2.85 & 2.28 & 2.57 & 2.32 & 2.59 & 2.61 (1.35 2.524 .03$)$ \\
\hline Asia (excluding Japan) & 2.28 & 2.61 & 2.37 & 2.47 & 2.46 & 2.44 & 2.41 & 2.47 & 2.44 (1.34 2.01 3.24) \\
\hline Eastern Europe & 1.69 & 2.12 & 2.12 & 1.83 & 2.15 & 2.26 & 1.89 & 1.77 & 1.96 (1.20 1.58 2.29) \\
\hline Mean (for all regions) & 2.77 & 3.17 & 2.83 & 2.93 & 3.06 & 3.18 & 3.21 & 3.10 & \\
\hline
\end{tabular}

whole period. USA and Canada are on the top of this list regarding the cumulative production of research in Infectious Diseases during the period 1995-2002. Interestingly, with the aforementioned adjustments Oceania ranks third on this list.

\section{Discussion}

Our study shows that USA and Western Europe make up a striking $80 \%$ of the world's research production in terms of both quantity and quality of articles published in Infectious Diseases journals. In addition, our study shows that scientific publications in Infectious Diseases journals increased from 1995 through 2002. The product of the number of published articles multiplied by the impact factor of the journals ("total product"), an index that estimates combined the quantity and quality of produced publications, also increased during the study period. The increased number of published articles in the Infectious Diseases journals, during the study period, is mainly attributed to the introduction of new titles of journals as well as an increase of the number of articles published in some of the journals in the field; both of these trends are mainly the result of increased demand for publishing due to increased production of research data $[12,13]$.

Another interesting finding in our study was the relative reduction in research productivity of the USA compared to the rest of the world. This finding was also observed in the past by other investigators including the U.S. share of research articles in the leading basic and clinical research articles $[14,15]$. These observations may reflect mainly the improvement of the scientific output, including biomedical research, by several world areas as a result of the general improvement of their economic indices rather than absolute worsening of these factors in the USA.
We provide some data about the relative contribution in research productivity of different world regions in the field of Infectious Diseases. This quantitative data may be used in comparing the productivity of areas of the world with diverse economic status and priorities for funding of different social needs. In addition, our data may be useful as baseline information in evaluating the return of investment on research in Infectious Diseases in areas of the world where this is needed most, i.e. in the developing countries. Specifically, our data show that USA and Canada are the most productive regions when population and GNIPC are taken into account. However, it is interesting that Africa ranks fourth in research productivity when adjustments for these two factors are made. When interpreting this result, one should take into account that a large part of the research originating from this region is the result of multinational/multiregional collaborations, a fact that was not evaluated in this study. Nevertheless, our analysis shows that articles produced by investigators in Africa represent an important scientific contribution to the field of Infectious diseases, due to the very low GNIPC of the area, as well as a satisfactory return of the resources invested for Infectious Diseases research in the area.

Our study has several limitations in both the collection and interpretation of data. First, we used JCR criteria for including medical journals in the study. Articles published in non JCR-cited journals were not included, although they contribute to scientific production [16]. Moreover, we used the JCR impact factor. Although the impact factor has often been criticized as a tool for measuring scientific research quality [17-19], thus far it has not been replaced by any other worldwide-accepted method. JCR uses several criteria in order to include a journal in its databases, and up today the impact factor represents the best method of biomedical journal categorization [20- 


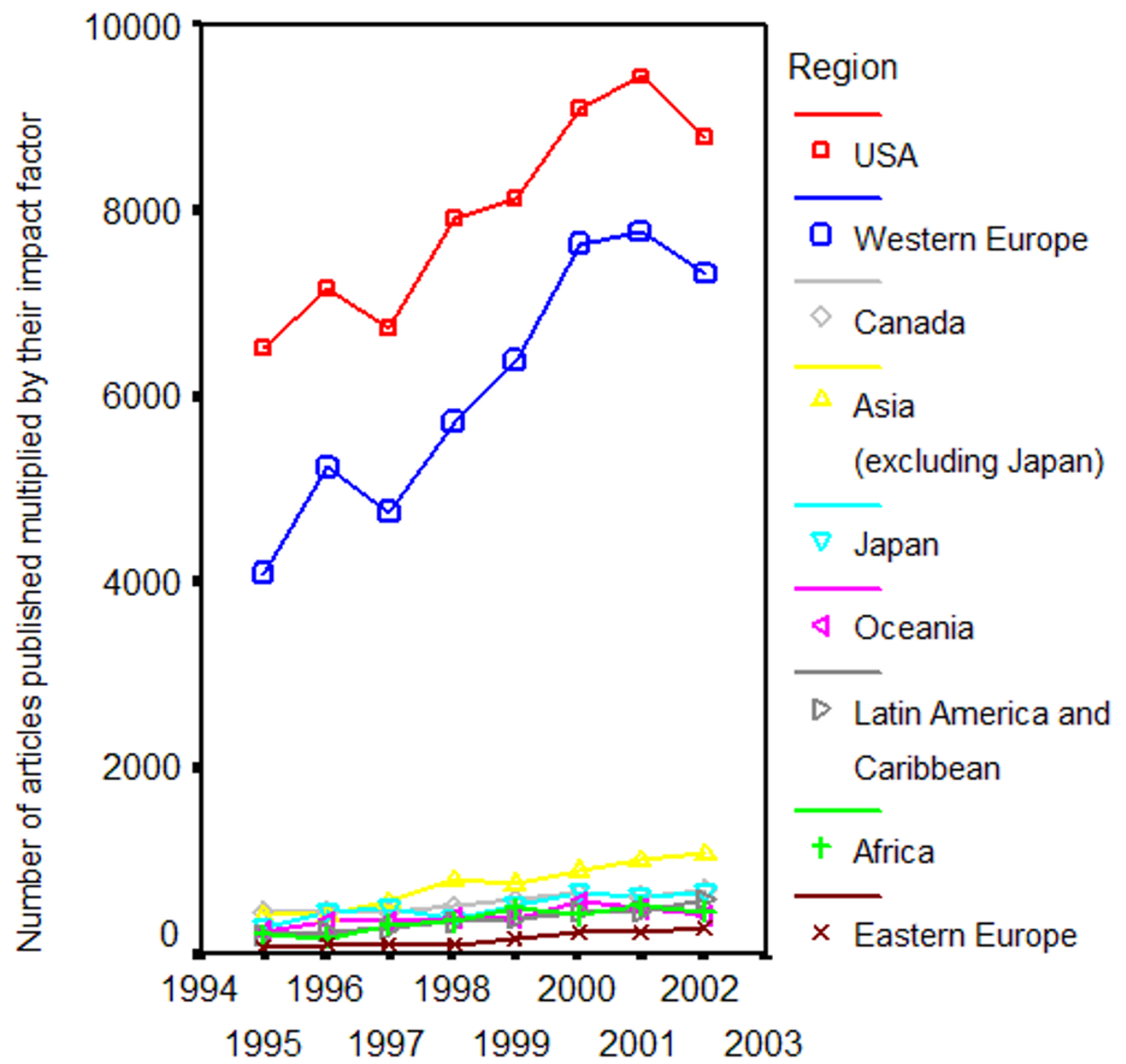

Year

Figure I

Graph displaying the worldwide trends of "total product" of research productivity (number of articles published multiplied by their impact factor) in Infectious Diseases, for different world regions, in the period 1995-2002.

22]. Also, we used the PubMed, which is an easily accessible and widely used database. Nevertheless, some scientific articles are not included in this database and consequently were not analyzed in our study. In addition, in PubMed only the address of the first author is regis- tered; thus studies that were created by multinational/ multi-regional cooperation were counted as originating from only one region of the world. Another problem with the collection of data was associated with the fact that the search system we created was not able to retrieve the 
Table 4: Research output of different world areas, published in journals included in the category of "Infectious Diseases" of the Institute for Scientific Information (ISI), adjusted for population and gross national income per capita (GNIPC).

\begin{tabular}{|c|c|c|c|c|c|c|c|c|c|}
\hline \multirow[b]{2}{*}{ WORLD AREAS } & \multicolumn{9}{|c|}{$\begin{array}{l}\text { Number of publications multiplied by the impact factor per million of population divided by } \\
\text { the GNIPC (in 10,000 } 1995 \text { US dollars per capita) }\end{array}$} \\
\hline & 1995 & 1996 & 1997 & 1998 & 1999 & 2000 & 2001 & 2002 & Average \\
\hline USA & 8.8 & 9.4 & 8.4 & 9.5 & 9.4 & 10.1 & 10.5 & 9.6 & 9.5 \\
\hline Canada & 7.7 & 7.9 & 7.1 & 8.4 & 8.8 & 9.5 & 8.9 & 9.6 & 8.5 \\
\hline Oceania & 5.3 & 7.4 & 6.9 & 7.8 & 7.4 & 10.2 & 8.5 & 7.6 & 7.6 \\
\hline Africa & 4.2 & 3.8 & 6.0 & 6.4 & 8.8 & 7.7 & 9.1 & 7.4 & 6.7 \\
\hline Western Europe & 4.5 & 5.7 & 5.0 & 5.9 & 6.4 & 7.4 & 7.4 & 6.9 & 6.2 \\
\hline Asia (excluding Japan) & 1.4 & 1.3 & 1.7 & 2.3 & 2.2 & 2.5 & 2.6 & 2.7 & 2.1 \\
\hline Latin America \& the Caribbean & 1.2 & 1.5 & 1.5 & 1.9 & 2.0 & 2.4 & 2.4 & 3.1 & 2.0 \\
\hline Eastern Europe & 0.8 & 0.9 & 1.2 & 1.2 & 1.6 & 2.1 & 2.0 & 2.4 & 1.5 \\
\hline Japan & 0.6 & 0.8 & 0.9 & 0.7 & 0.9 & 1.2 & 1.1 & 1.2 & 0.9 \\
\hline
\end{tabular}

addresses of all articles. However, we managed to retrieve $98.5 \%$ of all published articles by performing meticulous searches for the address of the first author. Therefore, we assumed that the number of missed articles did not significantly affect our study results.

Another limitation is associated with the division of the world into different regions. Our categorization takes into account geographic, economic, and, most importantly, scientific criteria but despite that, alternative approaches would also be appropriate. For example, Canada could be grouped together with USA, and Japan could be studied together with the other Asian countries. Nevertheless, Canada and Japan represent powerful autonomous scientific world regions and thus we examined them as separate regions. In addition, when interpreting the results, one should take into account that many articles regarding infectious diseases are published in journals of other JCR categories such as "Medicine, General and Internal", "Medicine, Research and Experimental", "Virology", and "Parasitology" and not in the "Infectious Diseases" category. However, we believe that this fact adds no systematic bias in the analysis of our data.

\section{Conclusion}

In summary, we evaluated the worldwide trends of research productivity in the field of Infectious Diseases during an 8-year recent period. The results of this study showed a reassuring trend; the fact that developing world regions achieved a higher rate of increase of research productivity than the developed world regions. This is probably the result of increased awareness about the significance of infectious diseases in the developing world regions as well as improved infrastructure supporting research and development in these areas.

\section{Competing interests}

The author(s) declare that they have no competing interests.

\section{Authors' contributions}

MEF conceived the idea for the study; IAB and PIV collected the data; KP and AIK did the statistical analysis; IAB drafted the manuscript; all authors contributed in the writing and preparation of the manuscript. All authors read and approved the final manuscript.

\section{References}

I. Keiser J, Utzinger J, Tanner M, Singer BH: Representation of authors and editors from countries with different human development indexes in the leading literature on tropical medicine: survey of current evidence. BM/ 2004, 328:1229-32.

2. Vergidis PI, Karavasiou Al, Paraschakis K, Bliziotis I, Papastamataki PA, Falagas ME: A bibliometric analysis of worldwide trends in research productivity in Microbiology. Eur J Clin Microbiol Infect Dis in press.

3. Rosmarakis ES, Vergidis PI, Soteriades ES, Paraschakis K, Papastamataki PA, Falagas ME: Estimates of global production in cardiovascular diseases research. Int J Cardiol in press.

4. Rahman M, Fukui T: Biomedical publication-global profile and trend. Public Health 2003, I I 7:274-80.

5. Ugolini D, Mela GS: Oncological research overview in the European Union. A 5-year survey. Eur J Cancer 2003, 39: I 888-94.

6. Mela GS, Martinoli C, Poggi E, Derchi LE: Radiological research in Europe: a bibliometric study. Eur Radiol 2003, 1 3:657-62.

7. Ramos JM, Gutierrez F, Masia M, Martin-Hidalgo A: Publication of European Union research on infectious diseases (1991200I): a bibliometric evaluation. Eur J Clin Microbiol Infect Dis 2004, 23: 180-4.

8. National Library of Medicine: Index Medicus database (PubMed), Bethesda, Maryland 2004.

9. Institute for Scientific Information. SCl: Science Citation IndexJournal Citation Reports, Philadelphia, The Institute for Scientific Information. 2004.

10. United Nations Statistical Yearbook: 42nd issue, CD-Rom Edition, United Nations, New York 2004.

II. World Development Indicators: The World Bank, Washington 2004.

12. Boldt J, Haisch G, Maleck WH: Changes in the impact factor of anesthesia/critical care journals within the past 10 years. Acta Anaesthesiol Scand 2000, 44:842-9.

13. Jemec GB: Impact factors of dermatological journals for I9912000. BMC Dermatol 2001, I:7. 
14. Stossel TP, Stossel SC: Declining American representation in leading clinical-research journals. N Engl J Med 1990, 322:739-742.

15. Rahman M, Fukui T: A decline in the U.S. share of research articles. N Engl J Med 2002, 347:121I-2.

16. Winkmann G, Schweim HG: [Medical-bioscientific databanks and the Impact Factor]. Dtsch Med Wochenschr 2000, | 25: || 33-4|.

17. Whitehouse GH: Impact factors: facts and myths. Eur Radiol 2002, I 2:7| $15-7$

18. Seglen PO: Why the impact factor of journals should not be used for evaluating research. BM] 1997, 3 | 4:498-502.

19. Barnaby DP, Gallagher EJ: Alternative to the Science Citation Index impact factor as an assessment of emergency medicine's scientific contributions. Ann Emerg Med 1998, 31:78-82.

20. Gensini GF, Conti AA: [The impact factor: a factor of impact or the impact of a (sole) factor? The limits of a bibliometric indicator as a candidate for an instrument to evaluate scientific production]. Ann Ital Med Int 1999, 14:130-3.

21. Garfield E: Citation indexes for science; a new dimension in documentation through association of ideas. Science 1955, I22: I08-II.

22. Luukkonen $\mathrm{T}$ : Bibliometrics and evaluation of research performance. Ann Med 1990, 22:145-50.

\section{Pre-publication history}

The pre-publication history for this paper can be accessed here:

http://www.biomedcentral.com/1471-2334/5/16/prepub

Publish with Biomed Central and every scientist can read your work free of charge

"BioMed Central will be the most significant development for disseminating the results of biomedical research in our lifetime. "

Sir Paul Nurse, Cancer Research UK

Your research papers will be:

- available free of charge to the entire biomedical community

- peer reviewed and published immediately upon acceptance

- cited in PubMed and archived on PubMed Central

- yours - you keep the copyright 